In: Language Sciences 34 (2012), 715-724.

\title{
Data, problems, heuristics and results in cognitive metaphor research
}

\author{
András Kertész ${ }^{a^{*}}$, Csilla Rákosi ${ }^{\mathrm{b}}$, Péter Csatár ${ }^{\mathrm{c}}$ \\ ${ }^{a, c}$ University of Debrecen, Institute of German Studies, Pf. 47, H-4010 Debrecen, Hungary \\ ${ }^{b}$ University of Debrecen, Research Group for Theoretical Linguistics, Pf. 47, H-4010 \\ Debrecen, Hungary \\ * Corresponding author. E-mail address: andras.kertesz@,t-online.hu
}

\begin{abstract}
Cognitive metaphor research is characterised by the diversity of rival theories. Starting from this observation, the paper focuses on the problem of how the unity and diversity of cognitive theories of metaphor can be accounted for. The first part of the paper outlines a suitable metascientific approach which emerges as a modification of B. von Eckardt's notion of research framework. In the second part, by the help of this approach, some aspects of the sophisticated relationship between Lakoff and Johnson's, Glucksberg's, and Gentner's theories are discussed. The main finding is that the data, the problems, the heuristics and the hypotheses which have been partly shaped by the rivals contribute to the development of the particular theories to a considerable extent.
\end{abstract}

Keywords: cognitive science, cognitive linguistics, metaphor, philosophy of science

\section{Introduction}

The data problem currently discussed in several fields of linguistics affects cognitive metaphor research as well. We raise it in its simplest form as follows:

(P1) What types of data can be used and how can these types of data be applied in cognitive theories of metaphor?

(P1) is a typical metatheoretical problem and should therefore be treated as such. Since the thesis of the theory-ladeness of data is one of the few tenets which in one version or other all approaches to the philosophy of science seem to accept, it follows that the nature of data in cognitive metaphor research cannot be detached from the nature of cognitive theories of metaphor. Therefore, the precondition for finding a possible solution to (P1) is to reveal the nature of the latter.

As is well-known, since the 1980s a rich network of alternative approaches to cognitive metaphor research has emerged. These theories suggested new solutions to old problems, raised new problems and developed new methods of research. Nevertheless, the relationship among the elements of this highly complex network is anything but clear. Proponents of a certain theory of metaphor either do not reflect on alternative approaches at all, or fiercely criticize and reject those (cf. e.g. Leezenberg, 2001; Glucksberg and McGlone, 2001; Jäkel, 1997; Baldauf, 1997; Haser, 2005; see also Schwarz, 2008, pp. 66-75, Skirl, 2009). Consequently, the present state of the art has two main characteristics. On the one hand, cognitive theories of metaphor necessarily have common features, since all of them define them- 
selves as being part of cognitive science. On the other hand, as regards their hypotheses and the methods they apply, they are incompatible in several respects. Thus, we face the problem of resolving the tension between these two aspects, namely:

(P2) How can we account for the unity and diversity of cognitive theories of metaphor?

The reason why no possible solutions to this problem could be found so far is the lack of an appropriate metascientific method which would facilitate investigating the complex and sophisticated relationships among cognitive theories of metaphor. This means that (P2) can be discussed only if (P3) has been answered:

Which metatheory can solve (P2)?

We will argue as follows. In Section 2, we will outline a possible solution to (P3). In Section 3 , this metatheory will be applied to (P2). Then, in Section 4 we will infer a possible solution to (P1) from our answer to (P2). Finally, our findings will be summarized in Section 5.

\section{On (P3)}

\subsection{Eckardt's research frameworks and subsidiary research frameworks}

Since Kuhn's The structure of scientific revolutions has been one of the most influential approaches to the history and philosophy of science, it seems to be a good starting point if we want to find a solution to (P3). However, it was argued among others by Barbara von Eckardt $(1993,2006)$ that Kuhn's approach is not applicable to cognitive science. The reason is that while Kuhn's account is intended to capture "mature" science only, cognitive science is an "immature" discipline in Kuhn's sense. According to Kuhn (1970), the main criterion for the maturity of a certain discipline is that it must have at least one paradigm. This means that "a Kuhnian paradigm (as well a disciplinary matrix and an exemplar) is either identical to a theory, contains a theory as one of its elements or consists in the application of a theory" (Eckardt, 1993, p. 373). As opposed to this, "it can be said with confidence that commitment to the FSC [framework of shared commitments] of an immature field does not involve commitment to some specific set of scientific theories" (Eckardt, 1993, p. 372-373). Cognitive science is an immature field in this sense. As Eckardt claims:

"What all cognitive scientists share over the course of time is a commitment to something like an approach to the study of mind rather than to some specific set of theories, explanations, or laws etc. It is not that the latter do not exist - surely they do. The point is, rather, that commitment or loyalty to such theories, explanations, or laws varies from research laboratory to research laboratory and from year to year (even from month to month). I take it that this feature of cognitive science [...] is what makes it an immature rather than a mature science. While a science is still immature, the theories that it generates are still tentative. They are on probation, so to speak, and they may become outmoded and be replaced by a new set of theories in the very near future. Yet when this happens the science does not change in an essential way. We do not stop doing cognitive science, for example, just because we decide that the specific theories of memory or language production that we accepted yesterday are wrong." (Eckardt, 1993, p. 15; emphasis as in the original) 
Kuhn's conceptual apparatus is restricted to capturing paradigms, scientific crises signifying the decline of paradigms, and scientific revolutions emerging from the crises. It cannot account for immature disciplines where paradigms have not yet developed, where one finds only a diversity of incompatible views on the foundations of the discipline, and a diversity of incompatible theories. Therefore, Eckardt suggests that the notion of research framework has to be introduced to replace the notion paradigm. According to Eckardt (2006, pp. 123-124), "a research framework consists of four sets of elements D, Q, SA, MA, where D is a set of assumptions that provide a pre-theoretical specification of the domain under study; Q is a set of basic empirical research questions, formulated pre-theoretically; SA is a set of substantive assumptions that embody the approach being taken in answering the basic questions and that constrain possible answers to those questions; and MA is a set of methodological assumptions". Introducing the notion of 'research framework' serves two purposes. First, it facilitates the analysis of a certain discipline on a pre-theoretical basis, and as a result of this, it captures the common properties of otherwise incompatible theories and captures the unity of cognitive science. Second, since it gives up the simplified distinction between "mature" and "immature" science, it can account for different phases of the development of disciplines by making use of a unified metatheoretical framework.

According to Eckardt, a scientific community accepts all the elements of a research framework and considers them not to be revisable. These irrevisable elements are supplemented by further elements, which are either not accepted by the whole of the scientific community or are restricted to specific sub-domains. These elements are revisable and constitute different subsidiary research frameworks. Therefore, one can explain the evolution of research frameworks by following the continuous change of their revisable elements, while the irrevisable ones remain unchanged (cf. Eckardt, 1993, p. 377-378).

Although Eckardt's suggestion is more flexible than Kuhn's, at least three reasons can be given to show that her proposal is not satisfactory, either. The first difficulty arises from the fact that Eckardt's approach is also one-sided, though not in the same sense as Kuhn's. Whereas Eckardt criticises Kuhn for his theory-centred perspective, she focuses solely on the other extreme, namely, on the pre-theoretical characterization of research frameworks. However, this is insufficient since one has to define the distinction between theoretical and pre-theoretical research in order to retain the pre-theoretical nature of research frameworks in cognitive science, something Eckardt fails to do. Second, as the indented quotation above shows, while she does not question the existence of theories within cognitive science, she does not develop means to describe the relations among these theories. Third, Eckardt herself emphasizes that research frameworks determine research only at a very high level of abstraction and they usually form only a set of implicit background hypotheses. As opposed to this, scientific problem solving presupposes more specific assumptions, methods and problems which are beyond the scope of the pre-theoretical nature of research frameworks (see e.g. Eckardt, 1993, p. 19-22).

From these considerations it follows that in order to account both for the unity and the diversity of cognitive theories of metaphor one cannot dispense with the characterization of the specific properties of theories. How can we carry out this task?

\subsection{Theoretical frameworks and subsidiary theoretical frameworks}

At this stage, there are two possible starting points for our discussion. First, Eckardt accepts the view that scientific inquiry is basically a problem solving procedure (cf. Eckardt, 1993, p. 24). Consequently, the description of scientific theories has to capture basic components of problem solving. Second, although different philosophies of science define the notion of 
theory in different ways, all of them agree on the fact that at least the following components closely related to problem solving are theory-dependent: (a) problems, (b) data ("empirical" data and background assumptions), (c) heuristics and (d) the results of problem solving, i.e. the hypotheses supported by the theory. If different theories define what they consider as problems, data, successful heuristics and the result of problem solving in completely different ways, then from the properties of these components - irrespective of how the concept theory is defined - one can draw certain conclusions concerning the differences among theories which otherwise accept the same research framework and subsidiary research framework.

We introduce the notion theoretical framework to refer to the set $\{\mathrm{P}, \mathrm{DA}, \mathrm{H}, \mathrm{R}\}$ where the symbols stand for problems, data, heuristics and results, respectively. In what follows we will call the particular stages of problem solving within a theoretical framework subsidiary theoretical frameworks. Whereas theoretical frameworks contain elements which are not regarded as revisable by the community accepting the theory, subsidiary theoretical frameworks include revisable elements as well (in addition to irrevisable ones).

These notions are intended to capture three important aspects. First, they facilitate synchronic comparison of theories belonging to the same research framework (or subsidiary research framework); thus, one can find overlapping features, similarities and differences among rival theories within a research framework and subsidiary research framework. Second, by describing the change of problems, heuristics, data and results one can also capture the diachronic process of the evolution of theoretical frameworks. Since scientific inquiry is conceived of as problem solving, philosophy and history of science must interpret theories in a dynamic manner. Therefore, following Rescher $(1976,1977)$, theories can be viewed as cyclic and prismatic reasoning processes. More specifically, the problems, data, heuristics and results at issue are continuously re-evaluated from different points of view within subsequent cycles of reasoning (see also Kertész and Rákosi 2009, 2012). The main stages of this process are embodied in different subsidiary theoretical frameworks. Third, by relating synchronic and diachronic analyses, it is possible to examine the influence which rival theories have on one another and to describe the complex relations among theories belonging to the same subsidiary research framework.

\subsection{The solution to (P3)}

The above considerations suggest the following solution to (P3):

(H3) (P2) can be solved by a metatheoretical approach consisting of four levels: research frameworks, subsidiary research frameworks, theoretical frameworks and subsidiary theoretical frameworks.

Obviously, completing the application of (H3) to (P2) lies out of the scope of the present paper. Therefore, its workability will only be illustrated by particular features of Lakoff and Johnson's cognitive theory of metaphor, Glucksberg's property attribution theory and Gentner's structure mapping theory. We make use of the following terminology. The term 'cognitive theories of metaphor' comprises all three approaches and within the latter, we will differentiate particular theories by the name of the authors. Since within Lakoff and Johnson's theory several stages of development - i.e. several subsidiary theoretical frameworks - can be differentiated, the term 'Lakoff and Johnson's cognitive theory of metaphor' will refer to the set of these subsidiary theoretical frameworks. See Figure 1 as an illustration of the four levels introduced above. 
level 1:

(a) nature: pre-theoretical; (b) structure: $\{\mathrm{D}, \mathrm{Q}, \mathrm{SA}$, MA\};

(c) elements: irrevisable elements accepted by the whole community of cognitive science

\section{level 2:}

(a) nature: pre-theoretical; (b) structure: $\{\mathrm{D}, \mathrm{Q}, \mathrm{SA}$, MA\};

(c) elements: irrevisable elements of level $1+$ revisable elements not accepted by the whole community of cognitive science

\section{level 3:}

(a) nature: theoretical;

(b) structure: $\{\mathrm{P}, \mathrm{DA}, \mathrm{H}$, $\mathrm{R}$ \}, superposed with the structure of level 2;

(c) elements: elements of levels 1, $2+$ irrevisable elements accepted by the whole community approving the given theory

\section{level 4:}

(a) nature: theoretical;

(b) structure: $\{\mathrm{P}, \mathrm{DA}, \mathrm{H}$, $\mathrm{R}$ \}, superposed with the structure of level 3;

(c) elements: elements of levels 1, 2, 3 + revisable elements not accepted by the whole community approving the theory

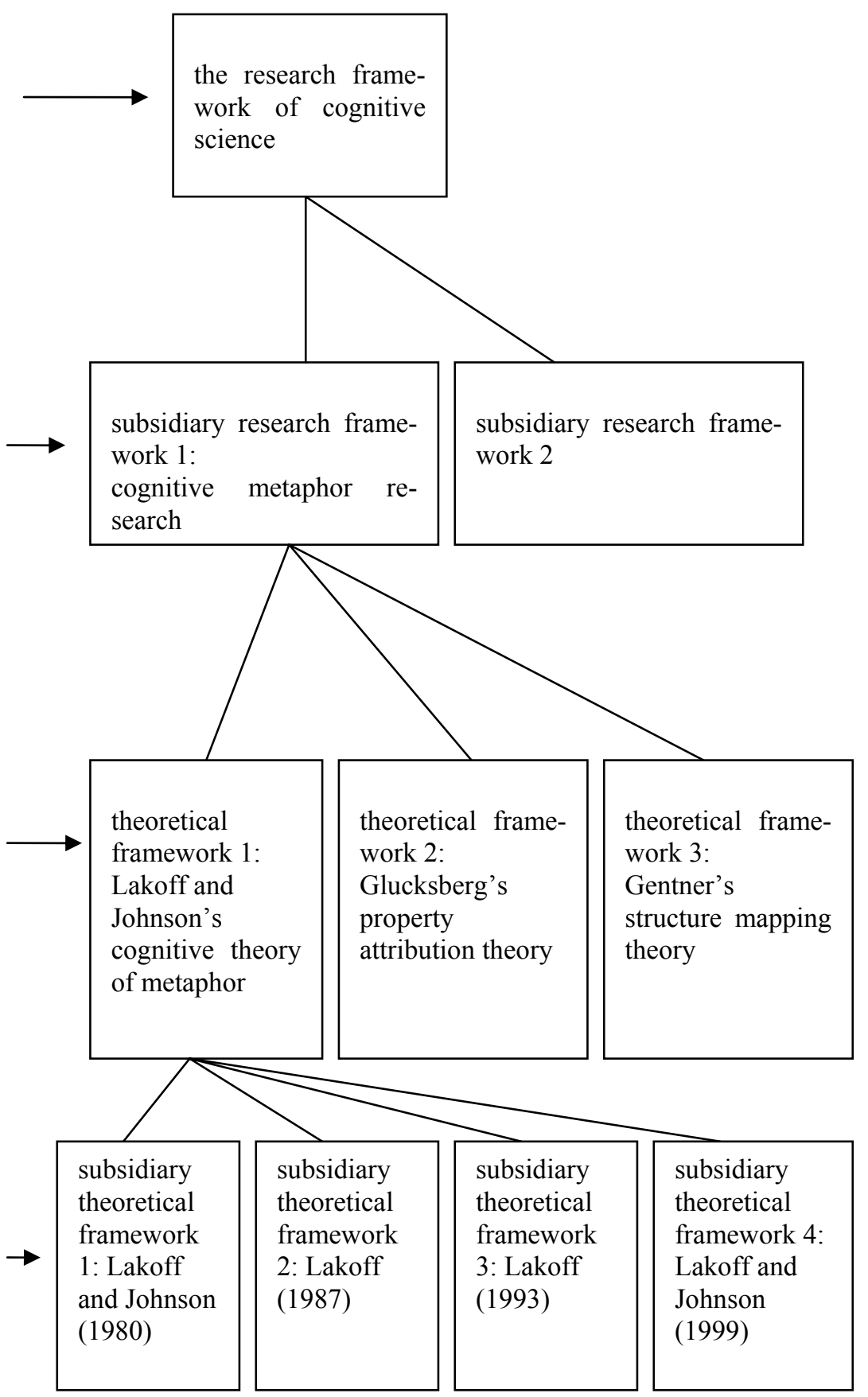

Figure 1: The four levels 


\section{On (P2)}

3.1. The research framework of cognitive science and the subsidiary research framework of metaphor research

From Eckardt's model it follows that cognitive science is the research framework of cognitive theories of metaphor. Those views whose domain is restricted to metaphor as a cognitive phenomenon form a particular subsidiary research framework. Hence, the unity of different theories of metaphor rests on two factors: the theories belong to the same research framework, namely, cognitive science; and, within the latter, they belong to the same subsidiary research framework.

The research framework of cognitive science contains, among others, the following elements (Eckardt, 2006, pp. 125-126):

Domain-specifying assumptions: The domain consists of human cognitive capacities.

Basic questions: For a normal, typical adult, what precisely is the human capacity to ?

How does a normal, typical adult exercise his or her capacity to

Substantive assumptions: The human, cognitive mind/brain is a representational device; hence, human cognitive capacities consist of a system of representational capacities. A representational device is a device that has states or that contains entities that are representations.

Methodological assumptions: Although there is considerable variation in how adult human beings exercise their cognitive capacities, adults are sufficiently alike when they cognize. Hence, it is meaningful to talk about a "typical" adult cognizer and it is possible to arrive at generalizations about cognition that hold (at least approximately) for all normal adults.

The elements constituting the subsidiary research framework of cognitive metaphor research can be illustrated by the following examples:

Domain-specifying assumptions: The domain consists of cognitive capacities for using and interpreting metaphoric expressions.

Basic questions: How can the nature of the human capacity which is applied when using and interpreting metaphoric expressions be described? What function do metaphors have in cognition? How are metaphors mentally represented? What kinds of metaphors are there and how do they differ with respect to structure and function?

Substantive assumptions: Metaphors do not simply form linguistic phenomena, they also have a cognitive function.

Methodological assumptions: Whatever be the characterization of metaphors, they should be investigated by using the empirical means of cognitive science.

\subsection{The three theoretical frameworks}

It will be sufficient to exemplify the diversity of theories within the subsidiary research framework of metaphor research by highlighting certain elements in the theoretical frameworks of the three rival approaches which are not accepted by the other two or are held to be irrelevant. See tables 1-4. 


\begin{tabular}{lll}
\hline $\begin{array}{c}\text { Lakoff and Johnson's cognitive } \\
\text { theory of metaphor }\end{array}$ & $\begin{array}{c}\text { Glucksberg's property attribution } \\
\text { theory }\end{array}$ & $\begin{array}{c}\text { Gentner's structure mapping the- } \\
\text { ory }\end{array}$ \\
\hline $\begin{array}{l}\text { What general principles govern the } \\
\text { interpretation and use of meta- }\end{array}$ & $\begin{array}{l}\text { How can the psychological process } \\
\text { phoric expressions, if we regard }\end{array}$ & $\begin{array}{l}\text { How can the psychological process } \\
\text { characterized, if we regard meta- }\end{array}$ \\
metaphors basically as one of the & phors as a kind of categorization? & characterized, if we regard meta- \\
phors as a kind of analogy? & Etc. \\
mental tools for structuring our ex- & Etc. & \\
periences? & & \\
Etc. &
\end{tabular}

Table 1: Problems 
cognitive theory of metaphor (Lakoff and Johnson)

Thinking and language rest on the same conceptual system, i.e. there is only one conceptual system underlying language and reasoning.

Metaphoric projection is always unidirectional.

There is systematicity among linguistic expressions in connection with abstract concepts and they build up complex systems. Etc.

$$
\begin{aligned}
& \text { property attribution theory } \\
& \text { (Glucksberg) }
\end{aligned}
$$

structure mapping theory

$$
\text { (Gentner) }
$$

Metaphors can always be transformed into similes and vice versa: metaphoric similes can be transformed into metaphors. In the case of literal similes, however, this transformation does not work.

The comprehension time of metaphors is influenced by the number of the topic's dimensions, such as its salient characteristics and by the unambiguity of the vehicle. Comprehension of metaphoric expressions does not take more time than that of literal expressions.

We understand metaphoric expressions faster than metaphoric similes.

Etc.
In neutral contexts the comprehension of metaphors in some cases requires a longer time than that of literal expressions.

Empirical evidence supports the claim that literal and metaphoric interpretations are processed not serially but simultaneously.

The conventionality of metaphors strongly influences the comprehension time: we interpret conventional figuratives faster than novel figuratives.

There is an interaction between the grammatical form and the degree of conventionality as well: novel similes are interpreted faster than novel metaphors, but in the case of conventional similes and metaphors we obtain the opposite result.

Etc.

Table 2: Data 
cognitive theory of metaphor (Lakoff and Johnson)

Properties of metaphorical concepts can be inferred from properties of metaphorical expressions.

Etc. property attribution theory (Glucksberg)

Psycholinguistic experiments. Examining differences between the behaviour of similes and metaphors and working out possible explanations.

Etc. structure mapping theory (Gentner)

Psycholinguistic experiments.

Explanation of differences in comprehension times by differentiating the concept metaphor and by working out a complex processing model.

Etc.

Table 3: Heuristics 


\begin{tabular}{|c|c|c|}
\hline $\begin{array}{c}\text { cognitive theory of metaphor } \\
\text { (Lakoff and Johnson) }\end{array}$ & $\begin{array}{c}\text { property attribution theory } \\
\text { (Glucksberg) }\end{array}$ & $\begin{array}{l}\text { structure mapping theory } \\
\text { (Gentner) }\end{array}$ \\
\hline $\begin{array}{l}\text { Metaphors have explanatory } \\
\text { power, i.e. they help us understand } \\
\text { different aspects of abstract con- } \\
\text { cepts. } \\
\text { The connection between the two } \\
\text { conceptual domains of metaphoric } \\
\text { expressions is a unidirectional } \\
\text { mapping between the source do- } \\
\text { main and the target domain. } \\
\text { The Invariance Principle: the } \\
\text { source domain preserves its struc- } \\
\text { ture during the metaphoric map- } \\
\text { ping. } \\
\text { The conceptual system is meta- } \\
\text { phorically structured. } \\
\text { Etc. }\end{array}$ & $\begin{array}{l}\text { Metaphorical expressions are cate- } \\
\text { gorical assertions. The vehicle re- } \\
\text { fers to a superordinate category } \\
\text { which does not necessarily have a } \\
\text { representation and a lexeme. } \\
\text { The vehicle has dual reference: it } \\
\text { refers to an abstract superordinate } \\
\text { category that is exemplified by the } \\
\text { vehicle and to a prototypical mem- } \\
\text { ber of that category, i.e. to the ve- } \\
\text { hicle as understood in its literal } \\
\text { sense. } \\
\text { The vehicle provides the property- } \\
\text { candidates which may be attributed } \\
\text { to the topic; the task of the topic is } \\
\text { to provide the local context where } \\
\text { the relevant properties will be se- } \\
\text { lected. } \\
\text { The selection and matching of the } \\
\text { relevant properties is an inference } \\
\text { process. } \\
\text { Etc. }\end{array}$ & $\begin{array}{l}\text { We always create manifold alter- } \\
\text { native interpretations (including } \\
\text { the literal one) and select the most } \\
\text { appropriate from them on the basis } \\
\text { of our background knowledge and } \\
\text { on the basis of the context. } \\
\text { The alignment of the } \\
\text { representation of the base and that } \\
\text { of the target domain is the result of } \\
\text { a continuous reinterpretation. } \\
\text { The base and the target domain ful- } \\
\text { fil different functions: the base of- } \\
\text { fers candidate inferences, thus it } \\
\text { gives new perspectives for the in- } \\
\text { terpretation of the target domain, } \\
\text { while the latter licenses them. } \\
\text { Not all metaphoric expressions can } \\
\text { be captured by one processing } \\
\text { model. There is a change in the } \\
\text { comprehension process corres- } \\
\text { ponding to their conventionaliza- } \\
\text { tion and lexicalization; the mode of } \\
\text { processing shifts gradually from } \\
\text { interpreting the expression as a } \\
\text { simile to interpreting it as a cate- } \\
\text { gorical assertion. }\end{array}$ \\
\hline
\end{tabular}

Table 4: Results 


\section{3. $\quad$ The solution to $(\mathrm{P} 2)$}

The above considerations yield the following hypothesis as the solution to (P2):

(H2) (a) The unity and common features of Lakoff and Johnson's cognitive theory of metaphor, Glucksberg's property attribution theory and Gentner's structure mapping theory are due to the fact that these theories belong to the same research framework, that of cognitive science, and within this, to the same subsidiary framework, that of cognitive metaphor research. There is a set of pre-theoretical basic questions and assumptions which are accepted by all of the theories in question. At the same time, they are associated with different theoretical frameworks, and thus the incompatible elements constituting the diversity of this scientific field become apparent as well.

(b) This kind of unity and diversity jointly facilitate continuous and manifold interaction among the three theories. The data, the problems, the heuristics, and the hypotheses which have been partly shaped by the rivals contribute to their development to a considerable extent.

\section{On (P1)}

\subsection{Introductory remarks}

Against the background of (H3) and (H2), our starting problem (P1) is to be interpreted in the context of what we have called the problems $P$, the heuristics $H$ applied, the results $R$ obtained and the data DA. In particular, in the next subsections we will discuss three examples. The first focuses on the connection between the problem of circularity and the data types used. The second example sheds light on the complex relationship between heuristics related to metaphor processing, experimental data, and the background assumptions. The third example highlights the importance of the combination of different data types and methods in the increasing of the reliability of the results.

\subsection{First example: the problem of circularity}

One of the main features of the relationship between the theoretical frameworks of cognitive metaphor research is that their proponents mutually accuse each other of circularity. These charges are directed against different aspects of the rival theories. Consider the following cases:

(a) Glucksberg's Property Attribution Theory (cf. Glucksberg, 2001, 2003) criticises Gentner's Structure Mapping Theory (cf. for example Gentner et al., 2001; Bowdle and Gentner, 2005; Gentner and Bowdle, 2001, 2008) as follows:

"Because the number of features that can be attributed in common to any two objects is unlimited [...], any theory of feature matching must either provide some mechanism for extracting subsets of features that are relevant in a given context or simply postulate prior feature selection and proceed from there. [...] The prior process of extraction and 
compilation, however, can be nothing other than the interpretation of the comparison assertion itself." (Glucksberg, 2001, p. 30)

(b) Interestingly, the target of the charge formulated by Lakoff and Johnson's cognitive theory of metaphor against Property Attribution Theory is the proposed model of metaphor processing, too:

"Jobs do not share the qualities that define jails in any literal sense, but only in a sense that is already metaphorical. For metaphors of this sort, both 'superordinate categories' and 'common properties' lead to a circular definition, inasmuch as they both rely on qualities that pertain to the vehicle literally but to the topic metaphorically. These qualities cannot be considered either 'common' or 'category-defining' until after the metaphorical work has already been accomplished." (Ritchie, 2003, p. 50; emphasis added)

(c) The Structural Similarity View (cf. for example Murphy, 1996, p. 179-180) raises the problem of circularity in connection with the restricted range of data types taken into consideration by Lakoff and Johnson's cognitive theory of metaphor:

"[...] the empirical base for the theory must be expanded beyond linguistic phenomena. As I pointed out in my analogy to the Whorfian hypothesis, there is a circularity here, such that linguistic data are used to identify metaphors, but the main concrete predictions the theory makes are about similar linguistic and psycholinguistic data. Since the theory is about conceptual representation, the kind of data familiar to cognitive psychologists should be predicted as well. That is, predictions about memory, problem solving, induction, measures of conceptual structure (such as typicality and categorization), learning and performance should become more central to the theory." (Murphy, 1996, p. 200; emphasis added)

The quotations above show that the charge of circularity is a central and relevant problem in current debates among adherents of diverse theoretical frameworks within the subsidiary research framework of metaphor research. The importance of this problem is due to the fact that it is regarded as a fatal failure, but its evaluation is in most cases contentious.

By way of illustration, let us mention a circularity-charge directed against the first subsidiary framework of Lakoff and Johnson's cognitive theory of metaphor. Lakoff and Johnson (1980) contained the heuristics according to which one can infer properties of metaphorical concepts from properties of metaphorical expressions. This method was seriously criticized by the Property Attribution Theory:

“[...] Lakoff's claim that metaphors transcend their linguistic manifestations to influence conceptual structure rests solely on these manifestations. How do we know that people think of theories in terms of buildings? Because people often talk about theories using building-related expressions. Why do people often talk about theories using buildingrelated expressions? Because people think about theories in terms of buildings. Clearly, the conceptual metaphor view must go beyond circular reasoning of this sort and seek evidence that is independent of the linguistic evidence." (McGlone, 2001, p. 95)

That is, McGlone considers the relation between the data and the hypotheses to be circular. According to his criticism, Lakoff and Johnson obtain one of the hypotheses of the theory (the existence of metaphorical concepts) from the data (metaphorical expressions), and then vice 
versa, they draw inferences related to the behaviour of the data from the hypothesis in question.

However, as it was shown in Kertész and Rákosi (2009), this heuristics does not inevitably result in circular argumentation. The reason is that by inferring the existence of metaphorical concepts from the use of metaphorical expressions and the use of metaphorical expressions from the existence of metaphorical concepts, "one indeed returns to 'the same point' but does so at a different cognitive level" (Rescher, 1987, p. 119). In particular, the difference between the two "cognitive levels" is that whereas one is methodological, the other is ontological. When we infer from the use of metaphorical expressions the existence of conceptual metaphors, then we are at the methodological level, or rather, in a methodological argumentation cycle. In this case, metaphorical expressions are regarded as primary and they work as data that serve as the starting point for linguistic theorising in agreement with the view according to which in cognitive linguistics "one can move freely and gradually from facts about language to facts about human cognition and further on to facts about human life generally" (Harder, 1999, p. 196). However, when the peculiarities of metaphorical expressions are explained by the existence of conceptual metaphors, then the argumentation proceeds at the ontological level, since it is an ontological assumption that metaphorical expressions are manifestations of metaphorical concepts, that is, the former are secondary, derived phenomena in comparison to the latter. Therefore, this method may be an effective heuristics, provided that one can explore more and more aspects of the connection between the two levels. To decide whether this is the case, or, rather, whether Lakoff and Johnson's argumentation is circular, further and more subtle considerations are needed.

According to McGlone, the source of the circularity is that it is solely linguistic data that have been applied. This stance presupposes that the use of a single data type leads inevitably and automatically to circularity. However, the use of a single data type does not lead necessarily to circularity because it is not the case that within a single data type no counterexamples against the hypotheses of the theory may appear. The reason why this is so is that the hypotheses of the theory have been obtained by inductive inferences in the methodological cycles. Therefore, they overgeneralise, i.e. they state more than they are allowed to on the basis of the cases examined. Thus, it could happen, for example, that in the ontological cycles, one comes across metaphorical expressions that do not display the kind of systematicity they should according to the hypothesis of the existence of conceptual metaphors. The possibility of conflicts between linguistic data and the hypotheses of the theory points towards the non-circular character of Lakoff and Johnson's argumentation. Such a judgement, however, would be overhasty, because Lakoff and Johnson systematically leave relevant linguistic data out of consideration; therefore, the testing of their hypotheses has to be deemed haphazard. First, there are many literal, non-metaphorical expressions related to abstract concepts. ${ }^{1}$ If we conceptualised arguments with the help of the metaphorical concept WAR, then it would not be the case that literal expressions are used to express aspects of the concept in question which the metaphor should be capable of explaining. These expressions clearly witness that several aspects of the given metaphor are left unexploited, since these are not realised in metaphorical expressions. The subsidiary theoretical framework of Lakoff and Johnson (1980), however, does not explain why certain aspects of the meaning of abstract concepts belong to the "used part" (cf. Lakoff and Johnson, 1980, p. 52-53) of a conceptual metaphor and why others pertain to the "unused part". A related problem is that it is not clear

\footnotetext{
1 For example, in the case of the concept ARGUMENT we have refute, confute, disprove, deny a statement, accept a motion, argue, argument, critical response, difference of opinion, assert a statement, establish a conclusion, discuss a problem, evidence for, convince somebody, assume an attitude, prove a statement etc.
} 
why we do not draw faulty "metaphorical entailments"2 concerning the target domain from the properties of the source domain, and why we do not draw "metaphorical entailments" that would in principle be possible - and consequently, why we do not use related metaphorical expressions. ${ }^{3}$ Second, Lakoff and Johnson do not pay enough attention to linguistic data testifying that with respect to abstract concepts, we often use metaphorical expressions which - according to the theoretical framework of the conceptual metaphor theory - should belong to different conceptual metaphors. From this, it should follow that these concepts were conceptualized with the help of more than one source domain, which were not isomorphic with each other. In that way, the target domain should have at the same time several structures. Accordingly, our thinking and behaviour should be governed (and not only influenced) by contradictory principles. Therefore, linguistic data which show that even within the boundaries of a single sentence expressions belonging to different metaphorical concepts may occur are also problematic. For example, if within the same sentence both of the following expressions occurred: discussion group which emphasizes the co-operative nature of the argument, and he has defended his position which belongs to the metaphor ARGUMENT IS WAR - then we would contradict ourselves. All this testifies that the ability of metaphors to influence our thinking and behaviour, if it exists at all, is quite restricted (see also Murphy, 1996, p. 184-188; Gentner et al., 2001, p. 207). Third, according to, for example, Haser (2005, p. 154), Lakoff and Johnson consider too small a set of metaphorical expressions as data insofar as they rely almost solely on familiar conventional metaphors (see also Keysar and Bly, 1995; McGlone, 2001, p. 95-96). From this it follows that Lakoff and Johnson's argumentation is circular even with respect to the treatment of linguistic data. Although in principle this need not be the case, because the application of a single data type in contrast to McGlone's view - does not lead automatically to circularity, we have shown that the testing of the hypotheses is not systematic, and this prevents the thorough reevaluation of the hypotheses of this theoretical framework.

A further important shortcoming of the treatment of data in Lakoff and Johnson (1980) is that, as is well-known, the reference to non-linguistic data remains an empty gesture. Although the growing field of psycholinguistic research posed a serious challenge for the conceptual metaphor theory, we find neither in Lakoff and Johnson (1980) nor in Lakoff (1993) arguments presenting and analysing results of psycholinguistic experiments or data stemming from other sources (cf. Murphy, 1996, p. 183-184; McGlone, 2001, p. 94-98). That is, while the preference of a single data type cannot be equated with circularity in the first subsidiary framework of Lakoff and Johnson's theory, in a longer run, taking into consideration the development of the theory, the neglect of other relevant data sources is a sign of circularity.

These brief analyses clearly indicate that the first and second subsidiary theoretical frameworks of the conceptual metaphor theory, despite their basically non-circular character, involve several circular aspects as well. The reason for this is that the argumentation process systematically ignores data that should be regarded as relevant, because their inclusion could significantly influence the plausibility of the hypotheses of the theory.

In the nineties, Lakoff and Johnson had to face further criticism on the part of their rivals. As a reaction to these attacks, a new subsidiary theoretical framework was put forward in Lakoff and Johnson (1999). For instance, in the new subsidiary framework the hypothesis about the unidirectionality of metaphorical structuring was supported by arguments from neuropsychology. Due to the criticism of property attribution theory and structure mapping theory new data types were used (such as evidence from neurology and developmental

\footnotetext{
2 'Metaphorical entailment' is Lakoff and Johnson's term, cf. Lakoff and Johnson (1980, p. 91-96).

For similar arguments, see McGlone (2007, p. 114); McGlone (2001, p. 94).
} 
psychology); their heuristics and background assumptions were also modified at several points.

We must not forget, however, that linguistic theories are highly complex. Therefore, in most cases it is not possible to decide at the outset whether a given theoretical framework corresponds to a cyclic argumentation process or to a circular one. First, it may happen that a theoretical framework is basically cyclic but includes circular stages as well. Second, the verdict on whether the theoretical framework as a whole is cyclic rather than circular or vice versa, cannot be based on the analysis of a single stage of its evolution, that is, on the examination of a subsidiary theoretical framework but one has to focus on the dynamism of its development. Therefore, in order to evaluate a theoretical framework in this respect, careful and thorough metatheoretical analyses of all of its subsidiary frameworks are needed.

Thus, with the evaluation of the new subsidiary framework Lakoff and Johnson (1999), we cannot narrow down our investigations to the analysis of the latter. We have to take into consideration - besides its predecessor subsidiary frameworks - the fierce criticism which has been levelled at the novel subsidiary theoretical framework of Lakoff and Johnson's cognitive metaphor theory (cf. Rakova, 2002; Leezenberg, 2001; Haser, 2005; Rohrer, 2006; Geeraerts, 2006), as well as the reactions of its proponents in order to decide whether it can meet this challenge. If it cannot, then its cyclicity will turn into circularity once again. If it can, then one may hope that the circularity can be avoided and the cyclic and prismatic argumentation process of conceptual metaphor research can be continued in an effective way.

\subsection{Second example: internal differentiation of the processing models}

The problem of circularity was instrumental in elaborating metaphor comprehension models associated with Gluckberg's property attribution theory and Gentner's structure mapping theory as well. Before Glucksberg's and Gentner's work, the field was dominated mainly by theoretical frameworks which regarded metaphors as implicit similes. These earlier theoretical frameworks inspired the psycholinguistic investigation of metaphors (i.e. the standard pragmatic model, cf. Loewenberg, 1975; Searle, 1993; Tversky's contrast model, cf. Tversky, 1977 or Ortony's salience imbalance model, cf. Ortony, 1979, Ortony et al., 1985).

However, these models were circular, since the selection of common features relied on the interpretation of the base of the similarity (cf. Glucksberg and McGlone, 2001, p. 30-31).

These theoretical frameworks have then been replaced, among others, by Glucksberg's and Gentner's. Since the latter strived to solve a common problem as well (namely, how to avoid the circularity of the processing model) and applied similar heuristics, one would expect a close similarity in the proposed hypotheses as well. However, this is not the case: the experimental data and background assumptions applied by the two theories contradicted each other in several respects, and both re-evaluated earlier results from different points of view. For example, according to Glucksberg, metaphors were categorical assertions, while in Gentner's opinion they were a specific kind of analogy. Despite this crucial difference, one cannot describe the relationship between the two theories as a sharp and stiff opposition or a fruitless debate. These controversies inspired the proponents of rival theoretical frameworks to develop more and more sophisticated heuristics, that is, psycholinguistic experiments. Hence, they tried to obtain new and more reliable data by improving the heuristics applied in order to cut the ground from under the critics' feet and to attack their rivals - but also to refine their model. The result was not only the elaboration of more sophisticated subsidiary frameworks, but adherents of both approaches came to the insight that there are phenomena which cannot be explained by their theory. The experimental data were compatible neither with Gluckberg's, nor with Gentner's theoretical framework. It is Gentner who has broken 
with the common background assumption of the other theories which state that the process of metaphor comprehension can be described by one mechanism only. Instead, she proposes the heuristics according to which differences in processing times related to different types of metaphors should be interpreted as signs of different modes of metaphor processing (cf. Bowdle and Gentner, 2005; Gentner et al., 2001; Gentner and Bowdle, 2008). On the basis of this heuristics, she argues for the result that since in the case of novel metaphors, both domains are at the same level of abstraction, i.e. they refer to their literal meaning, we interpret them as analogy (that is, as a comparison in which the target concept is structurally aligned with the base concept by projection of a series of inferences). In the case of conventional metaphors, the base becomes polysemous and both of its meanings (the concrete, literal and the abstract, metaphorical) can contribute to the interpretation of the metaphor. Thus, we can interpret conventional metaphors as comparisons or as categorical assertions as well, depending on the degree of conventionality. This hypothesis is very close to Glucksberg's proposal, although there are some differences as well.

As regards dead metaphors, she notes that the base has either already lost its primary (literal) meaning, or this meaning becomes totally irrelevant, hence such metaphors can be interpreted solely as categorization. In sum, according to the career of metaphor hypothesis, there is a change in the mode of processing parallel with the increasing conventionality and lexicalization. Gentner's theoretical framework also tries to integrate the finding of Lakoff and Johnson's theoretical framework according to which metaphors are not individual, isolated phenomena but create metaphor families ("extended systems of metaphors").

Thus, Gentner attempts to integrate the results of the other two theories into hers. She collects the open problems, and adopts and improves several of their data and heuristics. The acceptance or improvement of these new heuristics can have an immense influence on the whole of cognitive metaphor research. In fact, as Keysar et al. (2001) shows, adherents of the property attribution theory seem to accept Gentner's new heuristics, and they also try to explain the experimental data along these lines.

Discrepancies resulting from contradictory empirical data and background assumptions must not be equated with unproductive chaos; rather, they pave the way for the revision of the theoretical frameworks at issue. As we have seen in Sections 4.2 and 4.3, adherents of the theoretical frameworks return to the problems discovered or revealed by rival theories again and again, and re-evaluate the earlier decisions about the acceptance or rejection of statements, the reliability of the sources, the plausibility values of the statements, the workability of methodological norms, the conclusions previously reached by inferences etc. In sum: they retrospectively re-evaluate the information at issue (cf. Rescher, 1976, 1987; Kertész and Rákosi, 2009, 2012), elaborating new subsidiary frameworks. This successive reevaluation is initiated by considering new sources, new statements, new methods etc., and it leads to the elaboration of possible solutions to the problems. This process is basically not linear, because the re-evaluation of the information may raise new problems and need not lead immediately to the solution of ones raised earlier. ${ }^{4}$ This may require the revision of previous decisions, the assessment of further alternatives, and the evaluation and comparison of the alternative solutions. To sum up, retrospective re-evaluation is cyclic in nature. However, it is not only cyclic, it is also prismatic. This means that the cycles continuously change the perspective from which the pieces of information constituting the context are evaluated (cf. Rescher, 1987). Although different theoretical frameworks adopt basically different perspectives, they may (and should) look at the data, problems, heuristics and results from the rival's perspective, too. In this way, they can contribute to the development of the subsidiary research framework of cognitive metaphor research by (partial) cooperation as well.

4 For a considerably more precise description of this process see Kertész and Rákosi $(2009,2012)$. 


\subsection{Third example: The demand for the combination of data and methods}

Since language in cognitive science is treated as an integral part of cognition, it is commonplace in cognitive linguistics that the exploration of language in cognitive linguistics should be carried out in close cooperation with research in other cognitive disciplines. In the present context, this elementary methodological requirement means that investigations within the subsidiary research framework of the cognitive theory of metaphor should be carried out with respect to related research in cognitive science. Therefore, it is a fundamental question which data and methods from which branch of cognitive science can or should be combined with each other in order to discover the mental foundations of linguistic metaphors. ${ }^{5}$

Although all three theoretical frameworks outlined above (Lakoff and Johnson, Glucksberg, Gentner) are committed to the research framework of cognitive science, their relationship to the combination of methods and data is problematic insofar as they make use of only one kind of heuristics and data. The theoretical framework of Lakoff and Johnson (based on Lakoff and Johnson, 1980, 1993) is methodologically a genuine linguistic program. It makes use of the introspective-intuitive method and metalinguistic intuition as a source of data. ${ }^{6}$ The approaches of Gentner and Glucksberg are basically psychologically oriented and they use first and foremost psycholinguistic experiments as heuristics. Therefore, there seems to be a tension between the principle of cognitive commitment and the preference for a single data type and heuristic in research practice. From this, the question of possible extensions of the range of the applied data sources and heuristics and their combination by the three theoretical frameworks emerges.

This problem is a hot topic today. The main reason for this is that the introspectiveintuitive method of data collection technique as a principal heuristics was fiercely criticised by the rival theoretical frameworks mainly on the ground that it is unreliable, since it is subjective and can be influenced by many factors. Therefore, it is a serious challenge for cognitive metaphor research whether and how these problems can be solved. Adherents of Lakoff and Johnson's theoretical framework tried to respond to criticism levelled by psycholinguists (cf. e.g., Murphy, 1996, 1997; Glucksberg and McGlone, 2001; Keysar et al., 2000; Gentner et al., 2001; Gentner and Bowdle, 2008) in such a way that they partially reevaluated the data base and the heuristics (data-handling techniques) of the subsidiary theoretical framework Lakoff and Johnson (1980). As we will see, the following sources of data and heuristics have been suggested in current literature on cognitive research into metaphor: (i) metalinguistic intuition, (ii) corpus linguistic procedures and linguistic corpora, and (iii) psycholinguistic experiments and their results.

Proponents of the theoretical framework of Lakoff and Johnson basically followed two strategies in order to avoid problems arising from the overestimation of metalinguistic intuition:

Followers of the first strategy do not deny the merits of psycholinguistic data and heuristics, but they seem to think that testing the results of linguistic analyses falls outside their research field. Therefore, they propose different linguistic methods and/or data types which could allow the elimination of factors responsible for the unreliability of introspective data. ${ }^{7}$ In current literature, there are three main versions of this strategy: ${ }^{8}$

Cf. Sanders (1997) for an overview of the state of the art in the 90's and Gibbs $(2006,2008)$ for the present.

6 Gibbs' research activity could be mentioned as an exception, but even his approach is not without problems, as we will see in this section.

7 This is of course a competence problem, too. Ted Sanders noticed at an ICLA conference in the early 90's 
(i) One group of researchers argues for the explication of the introspective-intuitive method and its combination with other linguistic methods in order to arrive at a transparent and controllable procedure of data collection (Jäkel, 1997; Steen, 1999, 2007). Steen's approach, for example, can be considered as an attempt to explicate the introspective-intuitive method of data collection, allowing for the analysis of single metaphors. However, it still involves subjective and intuitive elements. Therefore, it cannot be regarded as a brand-new heuristics initiating a new subsidiary theoretical framework of the theory of Lakoff and Johnson. Other aspects of the framework also remain untouched by Steen's proposal. He concentrates solely on the explication of the introspective-intuitive method, so the problems concerning the absolute preference of linguistic data remain open.

(ii) There are metaphor researchers as well who think that the introspective-intuitive method can be controlled with the help of special linguistic procedures, i.e. by corpus linguistic methods. Therefore, they propose the combination of the introspective-intuitive method with corpus-based approaches and corpus data in order to solve the problem of the reliability of the results (cf. Deignan, 1999, 2008).

(iii) Some linguists want to eliminate the introspective-intuitive method totally (Stefanowitsch, 2006). They try to replace it by supposedly much more reliable data collection procedures, i.e. by corpus-based methods. Nevertheless, these radical views rest inevitably on metalinguistic intuition right at the outset and the evaluation of the results contains subjective elements, too (cf. Csatár, 2009, p. 38-41; Deignan, 1999, p. 180; Stefanowitsch and Gries (Eds.), 2007; Kertész and Rákosi, 2008).

In sum, the approaches mentioned above react to the problem of the reliability of the applied data and heuristics with the help of the application of new linguistic methods and linguistic data. They want to arrive at a renewed methodology by strengthening the linguistic base of cognitive metaphor research. In this way, however, the overestimation of linguistic heuristics and of the type of data, which is at the heart of the criticism put forward by the proponents of the rival theories, is not touched on by these approaches at all. They neither provide solutions to the problems raised by the rival theoretical frameworks (cf. e.g., Sections 4.2-3), nor do they answer criticism that could be directed against the heuristics and the data applied in corpus linguistics in general (Cf. Stefanowitsch and Gries (Eds.), 2007).

Some adherents of Lakoff and Johnson's theoretical framework follow a second strategy. Instead of elaborating a linguistically rooted course in order to renew the heuristics of the classical theoretical framework, their investigations are based on the combination of introspective-intuitive data with results of psycholinguistic experiments. Thus, as a consequence of the debates on the empirical foundations of Lakoff and Johnson's theoretical framework (cf. Murphy vs. Gibbs in Cognition, 1996, 1997) and the considerable success of rival theoretical frameworks (Glucksberg, 2001; Gentner, 1997; Bowdle and Gentner, 2005) a new direction has evolved: psycholinguistic research of conceptual metaphors (Gibbs, 2006, 2008).

Psycholinguists argue for the combination of linguistic and experimental evidence in order to solve the problem of the reliability and the overestimation of linguistic data:

\footnotetext{
that "a prominent cognitive linguist said: 'Sure, I think my theory could be tested in language processing, but I don't know how. That's other people's job."' (Sanders, 1997, p. 247). But even Sanders is of the opinion that psycholinguistic research is a basic source for reviewing cognitive linguistic analyses: "I consider it worthwhile to have a look at existing methods in psycholinguistics, to at least get some idea of possible manners to test linguistic theories." (Sanders, 1997, p. 248)

8 The problems related to the introspective-intuitive data collection techniques and metalinguistic intuition have been discussed in greater detail in Csatár (2009).
} 
"[...] linguistic metaphors should be treated as a source of hypotheses about the structure of abstract concepts. Evaluating these hypotheses - determining when a linguistic metaphor reflects an underlying conceptual metaphor - requires both linguistic and extralinguistic methods, and calls for cooperation across disciplines of the cognitive sciences." (Casasanto, 2009, p. 143; emphasis as in the original)

Psycholinguistic experiments, however, do not lead to certainly true results, either. First, they rely on subjective factors, too, for example, in connection with the judgement of metaphoricity, the degree of conventionality, etc. while elaborating the stimulus material. Therefore, psycholinguists are not in a position to ignore the problems of metalinguistic intuition. Second, several studies indicate that in spite of the application of measuring methods, we can find contradictory results related to the same topic. That is, some metaphor experiments came to mutually opposed results, for instance, on spatialising time in language and thought (cf. Casasanto, 2009, p. 130-131). Third, the problem of reproducibility indicates the same problem, for some of the experimental results could not be reproduced. Szamarasz repeated classic time-experiments (Boroditsky, 2000; Boroditsky and Ramscar, 2002) with Hungarian speakers, but her results yielded disparate results (cf. Szamarasz, 2006). Csatár, Pethö and Tóth tried to reproduce the results of an experiment of Gibbs (2002) on identifying and appreciating poetic metaphors, but the results were very divergent (cf. Csatár et al., 2006).

A further serious problem related to the experiments in favour of the theoretical framework of Lakoff and Johnson is that in most cases the authors do not aim at refuting the results of the rival theoretical frameworks. That is, they - unlike their rivals' adherents - do not try to identify the shortcomings of the experimental design applied by their critics and to elaborate more sophisticated and more reliable variants of their experiments.

To sum up, we can say that there seems to be a tremendous but yet unrealised and unexploited potential in the extension of the set of data types, the combination of different data types and the related methods. First, the combination of different data types may provide stronger evidence for a hypothesis than any of them alone. Second, the uncertainty resulting from the application of a single data type can be reduced by the combination of more data types and methods. Third, contradictions between hypotheses based on different data types require the re-evaluation of the hypotheses, methods etc., and with this, they contribute to the development of the given theoretical framework. ${ }^{9}$

\subsection{The solution to (P1)}

(H1) The metatheoretical approach to cognitive metaphor research as outlined above and summarised in (H2) and (H3), provides a plausible point of departure for capturing the following aspects of data in cognitive metaphor research:

(a) the interaction of different theoretical frameworks,

(b) as a result of this, the revision of data processing methods in the light of other theoretical frameworks,

(c) the retrospective re-evaluation process of data and data processing techniques which is at the heart of these mechanisms,

(d) the relationship between problems, heuristics and data.

9 For more on this, see Kertész and Rákosi (2012). 
Nevertheless, (H1) is the starting point, rather than the final result of applying the metatheoretical approach we have sketched to the data problem in cognitive metaphor research. To reveal the details and to check to what extent it is workable, there is a long way to go.

\section{Concluding remarks}

However simplified and concise the application of our metascientific model to cognitive metaphor research has been, it has illustrated the assumption that the continuous re-evaluation of problems, data, the heuristics employed and the results is not solely an outcome of the internal change of the theoretical framework at issue, but rather, stems from the stimuli coming from other theoretical frameworks belonging to the same research framework.

\section{Acknowledgements}

Work on the present paper was supported by the Research Group for Theoretical Linguistics of the Hungarian Academy of Sciences as well as the projects OTKA NI 68436 and TÁMOP 4.2.1./B09/1/KONV-2010-0007.

\section{References}

Baldauf, Ch., 1997. Metaphern und Kognition: Grundlagen einer neuen Theorie der Alltagsmetapher. Peter Lang, Frankfurt a. M. \& Berlin \& Bern \& New York \& Paris \& Wien.

Boroditsky, L., 2000. Metaphoric structuring: understanding time through spatial metaphors. Cognition 75(1), 1-28.

Boroditsky, L., Ramscar, M., 2002. The roles of body and mind in abstract thought. Psychological Science 13(2), 185-188.

Bowdle, B.F., Gentner, D., 2005. The career of metaphor. Psychological Review 112(1), 193216.

Casasanto, D., 2009. When is a linguistic metaphor a conceptual metaphor? In: Evans, V., Pourcel, S. (Eds.), New Directions in Cognitive Linguistics. John Benjamins, Amsterdam, Philadelphia, pp. 127-145.

Csatár, P., 2009. Data collection in metaphor research: old problems and new approaches. Sprachtheorie und germanistische Linguistik 19(1), 1-48.

Csatár, P., Pethö, G., Tóth, E., 2006. On possible factors in the aesthetic appreciation of metaphors. Journal of Literary Semantics 35, 59-71.

Deignan, A., 1999. Corpus-based research into metaphor. In: Cameron, L., Low, G. (Eds.), Researching and Applying Metaphor. Cambridge University Press, Cambridge, pp. 177199.

Deignan, A., 2008. Corpus linguistics and metaphor. In: Gibbs, R.W. (Ed.), The Cambridge Handbook of Metaphor and Thought. Cambridge University Press, Cambridge, pp. 280294.

Eckardt, B., 1993. What is Cognitive Science? The MIT Press, Cambridge \& London.

Eckardt, B., 2006. Cognitive science. In: Sarkar, S., Pfeifer, J. (Eds.), The Philosophy of Science. An Encyclopedia. Vol. 1. Routledge, New York, pp. 123-131. 
Gentner, D.,Wolff, P., 1997. Alignment in the processing of metaphor. Journal of Memory and Language 37, 331-355.

Gentner, D., Bowdle, B.F., 2001. Convention, form, and figurative language processing. Metaphor and Symbol 16, pp. 223-247.

Gentner, D., Bowdle, B., 2008. Metaphor as structure-mapping. In: Gibbs, R.W. (Ed.), The Cambridge Handbook of Metaphor and Thought. Cambridge University Press, Cambridge, pp. 109-128.

Gentner, D., Bowdle, B., Wolff, P., Boronat, C., 2001. Metaphor is like analogy. In: Gentner, D., Holyoak, K.J., Kokinov, B.N. (Eds.), The Analogical Mind: Perspectives from Cognitive Science. MIT Press, Cambridge, pp. 199-253.

Gibbs, R.W., 1994. The Poetics of Mind. Figurative Thought, Language, and Understanding. Cambridge University Press, Cambridge.

Gibbs, R.W., 1996. Why many concepts are metaphorical. Cognition 61, 309-319.

Gibbs, R.W., 2002. Identifying and appreciating poetic metaphor. Journal of Literary Semantics 31, 101-112.

Gibbs, R.W., 2006. Cognitive linguistics and metaphor research: past successes, skeptical questions, future challenges. D.E.L.T.A. 22: Especial, 1-20.

Gibbs, R.W., 2008. Metaphor and thought. The state of the art. In: Gibbs, R.W. (Ed.), The Cambridge Handbook of Metaphor and Thought. Cambridge University Press, Cambridge, pp. 3-13.

Glucksberg, S., 2003. The psycholinguistics of metaphor. Trends in Cognitive Science 7(2), 92-96.

Glucksberg, S., McGlone, M.S., 2001. Understanding Figurative Language: From Metaphors to Idioms. Oxford University Press, Oxford.

Harder, P., 1999. Partial autonomy, ontology, and methodology in cognitive linguistics. In: Janssen, T.A., Redeker, G. (Eds.), Cognitive Linguistics: Foundations, Scope, and Methodology. Mouton de Gruyter, Berlin \& New York, pp. 195-222.

Haser, V., 2005. Metaphor, Metonymy, and Experientialist Philosophy. Challenging Cognitive Semantics. Mouton de Gruyter, Berlin \& New York.

Jäkel, O., 1997. Metaphern in abstrakten Diskurs-Domänen. Peter Lang, Frankfurt am Main \& Berlin \& Bern \& New York \& Paris \& Wien.

Kertész, A., Rákosi, Cs., 2008. Conservatism vs. innovation in the (un)grammaticality debate. In: Kertész, A. and Rákosi, Cs. (Eds.), New Approaches to Linguistic Evidence. Pilot Studies / Neue Ansätze zu linguistischer Evidenz. Pilotstudien. Peter Lang, Frankfurt am Main \& Bern \& Bruxelles \& New York \& Oxford \& Wien, pp. 61-84.

Kertész, A., Rákosi, Cs., 2009. Cyclic vs. circular argumentation in the Conceptual Metaphor Theory. Cognitive Linguistics 20(4), 703-732.

Kertész, A., Rákosi, Cs., 2012. Data and Evidence in Linguistics: A Plausible Argumentation Model. Cambridge University Press, Cambridge.

Keysar, B., Bly, B., 1995. Intuitions about the transparency of idioms: can one keep a secret by spilling the beans? Journal of Memory and Language 34, 89-109.

Keysar, B., Shen, Y., Glucksberg, S., Horton, W.S., 2000. Conventional language: How metaphorical is it? Journal of Memory and Language 43, 576-593.

Kuhn, T.S., 1970. The Structure of Scientific Revolutions. Chicago University Press, Chicago.

Lakoff, G., 1987. Women, Fire, and Dangerous Things: What categories Reveal about the Mind. The University of Chicago Press, Chicago \& London.

Lakoff, G., 1993. The contemporary theory of metaphor. In: Ortony (Ed.), Metaphor and Thought. Cambridge University Press, Cambridge, pp. 202-252. 
Lakoff, G., Johnson, M., 1980. Metaphors We Live By. The University of Chicago Press, Chicago \& London.

Lakoff, G., Johnson, M., 1999. Philosophy in the Flesh. The Embodied Mind and its Challenge to Western Thought. Basic Books, New York.

Leezenberg, M., 2001. Contexts of Metaphor. Elsevier, Oxford.

Loewenberg, I., 1975. Identifying metaphors. Foundations of Language 12, 315-338.

McGlone, M.S., 2007. What is the explanatory value of a conceptual metaphor? Language \& Communication 27, 109-126.

McGlone, M.S., 2001. Concepts as metaphors. In: Glucksberg, S., McGlone, M.S., pp. 90107.

Murphy, G.L., 1996. On metaphoric representation. Cognition 60, 173-204.

Murphy, G.L., 1997. Reasons to doubt the present evidence for metaphoric representation. Cognition 62, 99-108.

Ortony, A., 1979. Beyond literal similarity. Psychological Review 86, 161-180.

Ortony, A., Vondruska, R.J., Foss, M.A., Jones, L.E., 1985. Salience, similes, and the asymmetry of similarity. Journal of Memory and Language 24, 569-594.

Rescher, N., 1976. Plausible Reasoning. Van Gorcum, Assen \& Amsterdam.

Rescher, N., 1977. Methodological Pragmatism. Blackwell, Oxford.

Rescher, N., 1987. How serious a fallacy is inconsistency? Argumentation 1, 303-316.

Ritchie, D., 2003. Categories and similarities: A note on circularity. Metaphor and Symbol 18(1), 49-53.

Sanders, T., 1997. Psycholinguistics and the discourse level: Challenges for cognitive linguistics. Cognitive Linguistics 8, 243-265.

Schwarz, M., 1992 ( $\left.{ }^{3} 2008\right)$. Einführung in die Kognitive Linguistik. Francke, Tübingen.

Skirl, H., 2009. Emergenz als Phänomen der Semantik am Beispiel des Metaphernverstehens. Narr, Tübingen.

Searle, J.R., 1993. Metaphor. In: Ortony (Ed.), Metaphor and Thought. Cambridge University Press, Cambridge, pp. 83-111.

Steen, G., 1999. From linguistic to conceptual metaphor in five steps. In: Steen, G., Gibbs, R.W. (Eds.), Metaphor in Cognitive Linguistics. John Benjamins, Amsterdam \& Philadelphia, pp. 57-77.

Steen, G., 2007. Finding Metaphor in Grammar and Usage: A Methodological Analysis of Theory and Research. John Benjamins, Amsterdam \& Philadelphia.

Stefanowitsch, A., 2006. Words and their metaphors: A corpus based approach. In: Stefanowitsch, A., Gries, S.T. (Eds.), Corpus-based Approaches to Metaphor and Metonymy. Mouton de Gruyter, Berlin, New York, pp. 64-105.

Stefanowitsch, A. \& Gries, S.T. (Eds.), 2007. Grammar without Grammaticality. Special issue of Corpus Linguistics and Linguistic Theory.

Szamarasz, V.Z., 2006. Az idő téri metaforái: a metaforák szerepe a feldolgozásban [Spatial metaphors of time: the role of metaphors in comprehension]. Világosság 8-9-10, 99-109.

Tversky, A., 1977. Features of similarity. Psychological Review 85, 327-352. 